Original research article

\title{
Versatile biomedical potential of biosynthesized silver nanoparticles from Acacia nilotica bark
}

\author{
Geeta Arya ${ }^{1}$, R. Mankamna Kumari ${ }^{1}$, Richa Pundir ${ }^{2}$, Sreemoyee Chatterjee ${ }^{2}$, Nidhi Gupta ${ }^{2}$, \\ Ajeet Kumar ${ }^{3}$, Ramesh Chandra ${ }^{4}$, Surendra Nimesh ${ }^{1 *}$ \\ ${ }^{1}$ Central University of Rajasthan, School of Life Sciences, Department of Biotechnology, Ajmer, Rajasthan, India \\ 2 The IIS University, Department of Biotechnology, Gurukul Marg, SFS, Mansarovar, Jaipur, Rajasthan, India \\ ${ }^{3}$ Clarkson University, School of Arts and Sciences, Department of Chemistry and Biomolecular Science, Potsdam, New York, USA \\ ${ }^{4}$ University of Delhi, Faculty of Science, Department of Chemistry, Delhi, India
}

\begin{abstract}
The present study reports the development of potent silver nanoparticles (AgNPs) using bark extract of Acacia nilotica and evaluation of its wound healing, anti-biofilm, anti-cancer and anti-microbial activity. Stable, small sized nanoparticles with spherical morphology were obtained after significant optimization studies that was evaluated through UV-visible spectroscopy. Thereafter, physicochemical characterization of biosynthesized AgNPs was carried out through DLS and FESEM for evaluation of size. EDAX and FTIR were carried out for the evaluation of composition and possible functional groups involved in the reduction and capping of AgNPs. The antibacterial potential was investigated through disc diffusion assay against Escherichia coli (E. coli) and Pseudomonas aeruginosa (P. aeruginosa). Further, the Congo Red Assay (CRA) successfully revealed the anti-biofilm activity against Bacillus subtilis (B. subtilis), Staphylococcus aureus (S. aureus), Proteus vulgaris (P. vulgaris), Pseudomonas aeruginosa (P. aeruginosa). Alamar blue assay was conducted in A549 cells to reveal the remarkable anticancer activity of biosynthesized AgNPs that resulted in a very appreciable manner. Further, the wound healing activity of AgNPs can heal the excised wound of mice up-to 100\% within 15 days. All these studies suggested that our biosynthesized AgNPs possess versatile biomedical application.
\end{abstract}

Keywords: Acacia nilotica; antibacterial; antibiofilm; anticancer; silver nanoparticles; wound healing

\section{Highlights:}

- Development of potent silver nanoparticles using bark extract of Acacia nilotica.

- Characterized the ANB-AgNPs via UV, DLS, FTIR, FESEM and EDAX.

- Evaluated of antibacterial and antibiofilm potential of ANB-AgNPs.

- Evaluated the anticancer and wound healing potential of ANB-AgNPs.

\section{Introduction}

Nanobiotechnology is a rapidly developing and promising field in biomedicine. Metallic nanoparticles have shown great potential in pharmaceuticals, industries and therapeutic field (Jeeva et al., 2014; Nakkala et al., 2014). Among metallic nanoparticles, silver has been gaining tremendous attention owing to their spectacular applications in the field of catalysis, photovoltaics and biomedicine. Silver nanoparticles possess properties including antimicrobial, antifungal, larvicidal and anti-parasitic (Vasanth et al., 2014). Along with this, silver nanoparticles synthesized through natural products have shown potent antioxidant (Ali et al., 2012) and catalytic properties (Balakumar et al., 2017; Vellaichamy and Periakaruppan, 2016 a, c). Silver nanoparticles are also known for their wound healing properties specifically green synthesized silver nanopar- ticles have been proven to exhibit significant wound healing action (Gong et al., 2018).

Further, cancer is becoming one of the leading causes of death in the world. The limitations of conventional approaches are acting as hurdles in therapeutics (Boisselier and Astruc, 2009; Ong et al., 2013). To overwhelm this dilemma, researchers are now moving to better alternatives that can surmount the problems. So, nanobiotechnology including AgNPs synthesized from plant extract can prove to be a promising substitute in cancer therapeutics as these are non-toxic and non-inflammatory. Numerous studies have investigated plants extracts for the biosynthesis of AgNPs such as Cinnamon zeylancium bark, Coleus amboinicus Lour, Medicago sativa, Citrus sinensis peel, Panax ginseng, Weissella oryza, Terminalia arjuna, Canarium ovatum, Cordia dichotoma, Cicer arientinum, Bacillus brevis, Justicia glauca, Bombax ceiba (Ahmed et al., 2016; Arya et al., 2016, 2017; Emmanuel et al., 2017; Kaviya et al., 2011; Ku-

\footnotetext{
* Author for correspondence: Surendra Nimesh, Central University of Rajasthan, School of Life Sciences, Department of Biotechnology, Bandarsindri, N.H. 8, Teh.-Kishangarh, Dist. - Ajmer - 305817, Rajasthan, India; e-mail: surendranimesh@gmail.com, surendranimesh@curaj.ac.in; http://doi.org/10.32725/jab.2019.010

Submitted: 2018-07-03 • Accepted: 2019-06-03 • Prepublished online: 2019-06-17

J Appl Biomed 17/2: 115-124• EISSN 1214-0287 • ISSN 1214-021X

(c) 2019 The Authors. Published by University of South Bohemia in České Budějovice, Faculty of Health and Social Sciences.

This is an open access article under the CC BY-NC-ND license.
} 
mari et al., 2016; Lukman et al., 2011; Narayanan and Sakthivel, 2011; Saravanan et al., 2018; Sathishkumar et al., 2009; Singh et al., 2016a, b; Vellaichamy and Periakaruppan, 2016b).

Acacia nilotica plant commonly known as Kiker and babul has been used in the medical field from ancient time owing to its medicinal values. Acacia nilotica is commonly found in almost all tropical and subtropical area of Africa, Asia, Australia. The plant was shown to have anti-mutagenic activity due to presence of phytochemicals i.e. polyphenols and gallic acid. Along with this, extract has been reported to exhibit cytotoxic activity (Ali et al., 2012).

In the present investigation, we have used bark extract of A. nilotica to facilitate green synthesis of AgNPs (ANB-ANPs). Though A. nilotica bark has earlier been employed for biosynthesis of AgNPs and evaluated for their antibacterial and catalytic activities (Prasad, 2015; Karuppiah et al., 2014; Preethy and Savitha, 2016), a systematic study exploring various dimensions of AgNPs synthesis is missing. Hence, this study was conducted where aqueous extract of A. nilotica bark was used for green synthesis of AgNPs and several parameters that influence the synthesis were investigated. The AgNPs were assessed by UV-visible spectrophotometry followed by further physicochemical characterization by DLS, FESEM, EDAX and FTIR. Further, their wound healing, anti-biofilm, antibacterial and anticancer activities analysis was performed. The antibacterial potential of ANB-ANPs was determined against $E$. coli and $P$. aeruginosa (a multi-drug resistant bacteria). For anti-biofilm activity, the AgNPs were assessed against two Gram-positive bacteria $B$. subtilis, $S$. aureus and two Gram-negative bacteria P. vulgaris, $P$. aeruginosa. Further, the anticancer activity of ANB-AgNPs was evaluated against A549 (human lung carcino$\mathrm{ma}$ ) cells. To evaluate the wound healing potential the excision and treatment study on mice model were performed.

\section{Materials and methods}

\section{Material}

Silver nitrate $\left(\mathrm{AgNO}_{3}, 99.99 \%\right.$, molecular weight $\left.=169.87\right)$, Luria broth and Luria Agar were purchased from Central Drug House, India. Dulbecco's Modified Eagle Medium high glucose (DMEM HG), Fetal Bovine Serum (FBS), 0.25\% Trypsin-EDTA were procured from Life Technologies, USA. Dulbecco's phosphate buffered saline (PBS) without calcium and magnesium chloride, Sodium bicarbonate, Resazurin sodium salt was purchased from Sigma Aldrich, India. Kanamycin was purchased from Himedia, India. Filtration was done using Whatman No. 1 filter paper and double distilled water (in-house prepared) was used for the preparation of extract and other solutions.

\section{Plant sampling}

Acacia nilotica bark samples were collected from the campus of Central University of Rajasthan, Ajmer. The samples were then separated, washed thoroughly with tap water followed by rinsing with DD water. The samples were then shade dried for 10-15 days.

\section{Preparation of aqueous extract of A. nilotica bark}

For this, dried barks were cut into small pieces and ground into fine powder by using mortar pestle. $10 \mathrm{~g}$ powdered bark was weighed and mixed in $100 \mathrm{ml}$ DD water. Further, it was boiled for $20 \mathrm{~min}$ at $60{ }^{\circ} \mathrm{C}$ under continuous stirring. The obtained mixture was then kept at room temperature to cool down and then filtered under reduced pressure condition. The clear filtrate was then used for reaction and kept at $4^{\circ} \mathrm{C}$ for further use.

\section{Biosynthesis of silver nanoparticles}

Aqueous bark extract was added drop-wise to $1 \mathrm{mM} \mathrm{AgNO}_{3}$ solution in an Erlenmeyer flask under continuous stirring at $500 \mathrm{rpm}$. The reaction was incubated until the color changed. The reaction mixture was then subjected to centrifugation at $10000 \mathrm{rpm}$ for $10 \mathrm{~min}$ followed by washing the pellet thrice with DD water. The obtained particles were then re-suspended, and their synthesis was confirmed by UV-visible spectrophotometer. The remaining pellet was dried for their further characterizations. The samples were later dried in vacuum for further studies.

\section{UV-visible spectrophotometer analysis}

The synthesized ANB-AgNPs were initially confirmed and characterized by UV-visible spectroscopy because of their unique characteristic properties. The AgNPs were analyzed through wavelength scanning ranging from $300-700 \mathrm{~nm}$. The obtained spectra were then used as a base for further characterization as it gives a rough idea about shape, size and yield of the synthesized particles.

\section{Optimization of reaction parameters}

The bio-fabrication of AgNPs is a very sensitive reaction in terms of size, shape, yield and agglomeration state that are influenced by certain important parameters. Here, we have optimized these parameters including the effect of reaction time, $\mathrm{AgNO}_{3}$ concentration, ratio of extract to $\mathrm{AgNO}_{3}$ and temperature of the reaction.

Firstly, the time of the reaction was optimized by performing reaction for stipulated time points of $10,20,40,60,80$, 120, 160 and $200 \mathrm{~min}$. The concentration of $\mathrm{AgNO}_{3}$ and the extract volume was kept constant for each reaction. Further, the reaction mixtures were subjected to centrifugation at 1000 rpm for $10 \mathrm{~min}$, washed thrice and dispersed in DD water. After sonication, the fully dispersed AgNPs were monitored through UV-visible spectrophotometer. The data procured was then used as the base information for next optimizations.

Further, the effect of different $\mathrm{AgNO}_{3}$ concentrations (0.5 mM, $1 \mathrm{mM}, 1.5 \mathrm{mM}$ and $2 \mathrm{mM}$ ), extract to $\mathrm{AgNO}_{3}$ ratios (1:40, $1: 20,1: 10,1: 6.5$ and $1: 5$ ) and effect of various reaction temperatures $\left(4^{\circ} \mathrm{C}, 25^{\circ} \mathrm{C}, 40{ }^{\circ} \mathrm{C}, 60^{\circ} \mathrm{C}\right.$ and $80^{\circ} \mathrm{C}$ ) were optimized in the same manner by keeping the other two parameters fixed and the reaction were exposed to UV-visible spectrophotometer.

\section{Microwave assisted synthesis of silver nanoparticles}

The biosynthesized reaction of AgNPs was also performed by irradiating the reaction mixture by microwave using the above optimized data. The bark extract was added drop-wise to $\mathrm{AgNO}_{3}$ solution and the reaction mixture was then irradiated for $30 \mathrm{~s}$ at $900 \mathrm{~W}$ of power. Color of the reaction changes after $30 \mathrm{~s}$ and the reaction mixture was then subjected to centrifugation followed by washing of obtained AgNPs pellet. Further, the same steps were followed for 60,90 and $120 \mathrm{~s}$ the color of reaction changed rapidly followed by analysis on UV-visible spectrometer at regular time intervals (i.e. 30, 60, 90 and $120 \mathrm{~s}$ ).

\section{Physicochemical characterization of ANB-AgNPs}

The very first characterization was done with UV-visible spectrophotometer because it confirmed the synthesis of AgNPs and gives a rough qualitative idea about size, shape and agglomeration state. For further quantitative confirmation of all these properties, the nanoparticles were subjected to DLS and FESEM. EDAX and FTIR were carried out to evaluate the com- 
position and possible functional groups involved in reduction and capping of AgNPs.

\section{Evaluation of antibacterial activity using disc diffusion assay}

To evaluate the antibacterial activity of the synthesized ANB-AgNPs, disc diffusion assay was executed against $E$. coli and $P$. aeruginosa. The experiment started with a single colony of both the bacteria that were obtained through streaking the glycerol stock of each of them on LB agar plates. The single colonies were picked and inoculated into LB broth followed by incubation at $37{ }^{\circ} \mathrm{C}$ for $16 \mathrm{~h}$ at $150 \mathrm{rpm}$ for primary culture. From the primary culture, $1 \%$ inoculum was inoculated in fresh broth and incubated to grow till 0.4 optical density at $600 \mathrm{~nm}$. From that, $100 \mu \mathrm{l}$ of the culture of each bacterium was spread on separate LB agar plate and sterile six paper discs $(5 \mathrm{~mm})$ were placed. Four of them were impregnated with different concentrations of ANB-AgNPs $(0.25-1 \mu \mathrm{g})$. Remaining discs were used as the negative and positive control by saturating with de-ionized water and antibiotic (kanamycin $1 \mu \mathrm{g} / \mathrm{ml}$ ), respectively. The plates were then kept at $37{ }^{\circ} \mathrm{C}$ for $24 \mathrm{~h}$ and zone of inhibition was measured.

\section{Anti-biofilm activity of ANB-AgNPs by CRA plate method:}

To evaluate the antibiofilm activity of ANB-AgNPs, Congo red agar (CRA) plate method was performed (Ansari et al., 2015; Kalishwaralal et al., 2010). Here in this method, a special media- brain heart infusion (BHI) broth supplemented with 5\% sucrose, $1 \%$ agar and $0.08 \%$ Congo red was utilized against four biofilm forming bacteria including $B$. subtilis, $S$. aureus, $P$. vulgaris, $P$. aeruginosa. The plates were prepared and after solidification the colonies of bacteria were inoculated on separate plates with and without ANB-AgNPs and inoculated aerobically at $37^{\circ} \mathrm{C}$ for $24-48 \mathrm{~h}$.

Evaluation of anticancer activity against $\mathbf{A 5 4 9}$ cell line To evaluate the anticancer activity of ANB-AgNPs, Alamar blue assay was performed against A549 cells. The cells were continuously grown in DMEM media with $10 \%$ FBS, $1 \%$ penstrep and maintained in $5 \% \mathrm{CO}_{2}$ at $37{ }^{\circ} \mathrm{C}$ in $\mathrm{CO}_{2}$ incubator. A flask with $80-85 \%$ confluency was used for the experiment followed by trypsinization and cell counting. Cells were seeded in 96 well plate at a cell density of $1 \times 10^{4}$ cells/well and were allowed to grow for $24 \mathrm{~h}$. After that, used media was discarded and cells were washed with PBS. Further treatment of different concentrations $(10-200 \mu \mathrm{g})$ was given to A549 cells to evaluate the anticancer property and likewise, treatment was given to HEK293 cells in a concentration of 3-100 $\mu \mathrm{g}$. After that, the used mixture was discarded and fresh mix of media and Alamar blue reagent (resazurin $0.15 \mathrm{mg} / \mathrm{ml}$ ) in a volume ratio of $90 \mu \mathrm{l}+10 \mu \mathrm{l}$ was added to each well along with the positive control. The absorbance was then measured at 570 and $600 \mathrm{~nm}$ using a microtiter plate reader after $4 \mathrm{~h}$.

\section{Animal experiment for wound healing}

The animal ethical committee of The IIS University approved the use of mice used in experiments and approved the protocols used.

\section{Preparation of ointment}

For topical application, an ointment was prepared using ANB-AgNPs along with Carbopol which forms a hydrogel after combining with water. The prepared combination of ANB-AgNPs-Carbopol hydrogel was used as topical applicator for wound healing experiment whereas only Carbopol hydrogel and Povidine-Iodine were used as negative and positive control, respectively (Moideen et al., 2011).

\section{Excision and treatment of wound}

Six to eight-week-old mice weighing about 100-700 g were used to evaluate the wound healing potential of ANB-AgNPs. All the experimental procedure and animal care were performed according to the guidelines of National Institute of Health Guide for the care and use of laboratory animal. All the mice were kept on a 12-hour light/dark cycle in a room at 22-25 ${ }^{\circ} \mathrm{C}$ with proper ventilation, and supplied with standard pellet diet and water regularly. One day before, the mice were shaved through the dorsal side of their body. Using a dermatological pencil, $10 \mathrm{~mm}$ mark was made on the shaved skin and the marked portion was cut through a sterile surgical blade under anesthetic condition (Gong et al., 2018; Wilkinson et al., 2011).

After excision, all the mice were randomly divided into three groups ( $n=5$ for each group) which includes group-I considered as the negative control where only Carbopol hydrogel was used as ointment applicator. Group-II included the Carbopol hydrogel having ANB-AgNPs as ointment applicator and group-III included positive control where Povidine-Iodine was used. The wound was treated by the ointment after subsequent days.

\section{Percentage of wound healing}

The percentage of wound healing or wound reduction was determined by calculating the ratio of reduction of size from the day of excision with an interval of four days. A reduction curve was plotted by calculating the percentage of wound healing through a mean of meter ruler in all three groups on 1st, 6th, 10 th and 15th days. The formula for calculation of wound healing is as follow:

$$
\% \text { of } W H=\left(W A_{0}-W A_{n} / W A_{0}\right) \times 100
$$

Where

$$
\begin{aligned}
& \mathrm{WH}=\text { Wound healing } \\
& \mathrm{WA}_{0}=\text { Wound area on day } 0 \\
& \mathrm{WA}_{\mathrm{n}}=\text { wound area on day } \mathrm{n}(n=1,6,10 \text { and } 15)
\end{aligned}
$$

\section{Statistical analysis}

All the experiments were done in duplicates, with three separate experiments to demonstrate reproducibility. All the data were presented as mean \pm standard deviation $( \pm S D$ ) of all the experiments.

\section{Results and discussion}

\section{Preparation of extract from A. nilotica bark}

A clear, light brown color aqueous extract of $A$. nilotica bark was obtained after boiling and filtration. The extract can be stored at $4{ }^{\circ} \mathrm{C}$ and used up to $2-3$ weeks. the extract should be kept on room temperature before reaction.

\section{Biosynthesis of ANB-AgNPs}

The biosynthesis reaction of AgNPs by bark extract resulted in the change of color from light yellow to a dark grayish solution that visually confirmed the synthesis of AgNPs (Fig. 1A). This was due to the action of the phytochemicals present in the extract including phenolic compounds and other secondary metabolites. The major constituent of the extract is secondary 
metabolites including cardiac glycosides, flavonoids, saponins, and tannins, as reported by Singh et al. (2016a, b). The main role of the reducing agent is to provide electrons to ions to form atoms and when matter is sized down, there is a huge raise in its surface free energy. This leads to increase in both chemical and physical interaction of the particles with its surrounding, introducing aggregation of these atoms that leads to rise in nano sized particles. Reducing agents have potential to reduce $\mathrm{Ag}^{+}$into $\mathrm{Ag}^{0}$ and their stabilization by capping.
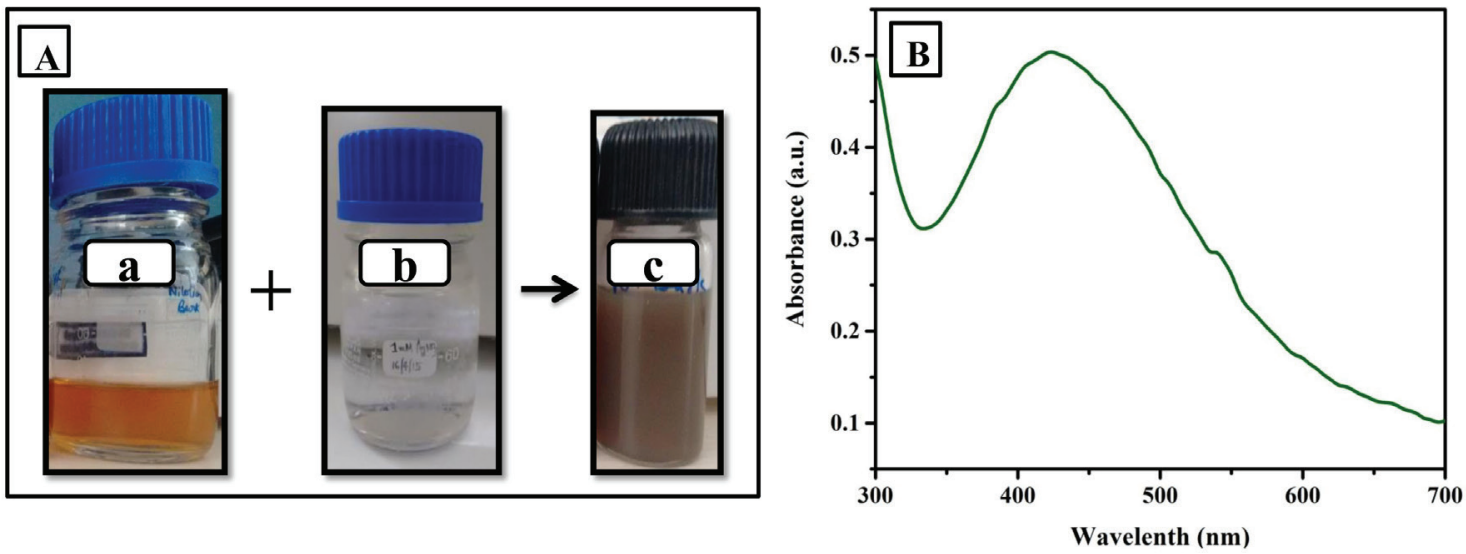

Fig. 1. (A) Biosynthesis reaction of AgNPs via Acacia nilotica bark (a) bark extract; (b) $\mathrm{AgNO}_{3}$ solution; (c) color change due to AgNPs synthesis. (B) UV-visible spectra showing SPR peak around $420 \mathrm{~nm}$. (For colour resolution see the on-line edition)

\section{UV-visible spectrophotometer analysis}

The UV-visible spectrophotometer has been largely employed for the characterization of AgNPs synthesis. These nanoparticles have been observed to exhibit characteristic strong surface plasmon resonance (SPR) band near $420 \mathrm{~nm}$. This occurs due to the collective oscillation of free electrons of the conduction band after excitation by a particular wavelength of incident light (Ajitha et al., 2016; Pradeepa et al., 2014). The graph distribution procured from this study gives the estimated information about the size, shape, yield and agglomeration state of AgNPs.

Ample amount of reports has been generated based on UV-visible spectra analysis of AgNPs. According to them, AgNPs with spherical shape give the absorbance maxima around $420 \mathrm{~nm}$ with one single peak or SPR band. However, particles having different shapes i.e. cuboid, rod, triangle etc. tend to show two or more peaks of SPR band (Mie, 1976). Further, the bathochromic shift of SPR band indicates larger particles size formation. Similarly, hypsochromic shift indicates the decreased particle size with stability (Stamplecoskie and Scaiano, 2010; Zhang et al., 2007). Reports also revealed that an increase in the SPR band in terms of absorbance or height indicates the increase in yield of AgNPs, but as the yield increases, aggregation is likely to occur which is due to the increase in collision frequency of AgNPs (Sathishkumar et al., 2009; Zhang et al., 2007).

Here, synthesized ANB-AgNPs were scanned using UV-visible spectrophotometer for confirmation of their synthesis. The optimization studies were done with the procured data (Fig. 1B). AgNPs biosynthesis here showed SPR band at $420 \mathrm{~nm}$ with a single peak, that tends to show spherical shape with smaller size and for quantitative confirmation, further physicochemical studies were executed.

\section{Optimization of reaction parameters}

The study of optimization of the parameter is very significant and essential due to the sensitivity of synthesis reaction for AgNPs that controls size, shape, yield and agglomeration state. The absorbance spectrum of ANB-AgNPs (Fig. 2A) was obtained at different time points which revealed that at reaction time $20 \mathrm{~min}$, the absorbance maxima of SPR was obtained around $420 \mathrm{~nm}$. Wherein at other time points $(40,80,120,160$ and $200 \mathrm{~min}$ ), the absorbance maxima showed bathochromic shift (near 435 and $440 \mathrm{~nm}$ ) indicating larger particles formation (Stamplecoskie and Scaiano, 2010; Zhang et al., 2007). So, $20 \mathrm{~min}$ of synthesis could be considered as optimized time for the reaction. Further, in the case of $\mathrm{AgNO}_{3}$ concentration, $0.1 \mathrm{mM}$ and $0.5 \mathrm{mM}$ showed very low yield along with hypsochromic shift at $410 \mathrm{~nm}$ (Fig. 2B). On the other hand, $1.5 \mathrm{mM}$ and $2 \mathrm{mM} \mathrm{AgNO}_{3}$ showed absorbance spectra with bathochromic shift including very high yield that could result in aggregation (Sathishkumar et al., 2009). The SPR band of $1 \mathrm{mM} \mathrm{AgNO}_{3}$ obtained near $420 \mathrm{~nm}$ henceforth suggested it to be the optimized concentration for ANB-AgNPs synthesis. Next optimization was done for extract to $\mathrm{AgNO}_{3}$ ratio. The procured data from UV-visible spectra (Fig. 2C) suggested that 1:20 $(0.5 \mathrm{ml}$ of extract) shows the absorbance spectra near $420 \mathrm{~nm}$ with the considerable amount of yield. Whereas in case of $1 \mathrm{ml}$ extract, the yield obtained was high along with a red shift near $440 \mathrm{~nm}$ suggesting larger particle size because of aggregation due to the collision of higher amount of AgNPs (Sathishkumar et al., 2009, Zhang et al., 2007). Similarly, in case of temperature optimization, the spectrum (Fig. 2D) revealed that $25^{\circ} \mathrm{C}$ temperature is suitable for ANB-AgNPs synthesis.

\section{Microwave assisted synthesis of silver nanoparticles}

The biosynthesis reaction of AgNPs was further conducted by microwave synthesis using the above-optimized parameters. The UV-visible scan data was obtained at regular time intervals at 30, 60, 90 and $120 \mathrm{~s}$ (Fig. 3). The obtained results indicated that the microwave assisted synthesis of nanoparticles was achieved in shorter duration of time. The color change was observed within $10 \mathrm{sec}$ indicating the reduction of $\mathrm{AgNO}_{3}$ leading to formation of nanoparticles. 

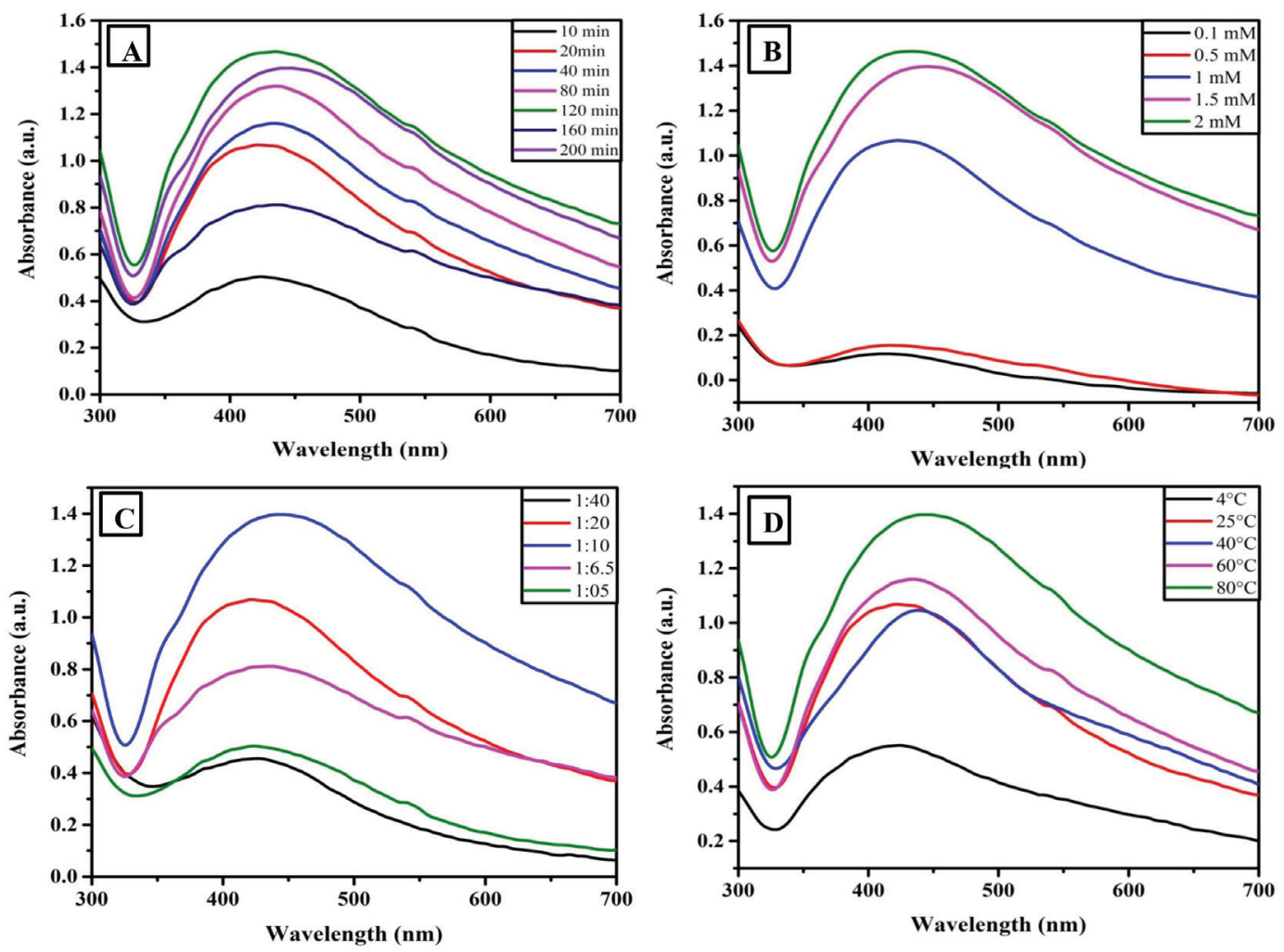

Fig. 2. UV-vis spectra of the optimization studies including $(\mathbf{A})$ reaction time; $(\mathbf{B}) \mathrm{AgNO}_{3}$ concentrations; (C) extract to $\mathrm{AgNO}_{3}$ ratio; $(\mathbf{D})$ temperature of reaction. (For colour resolution see the on-line edition)

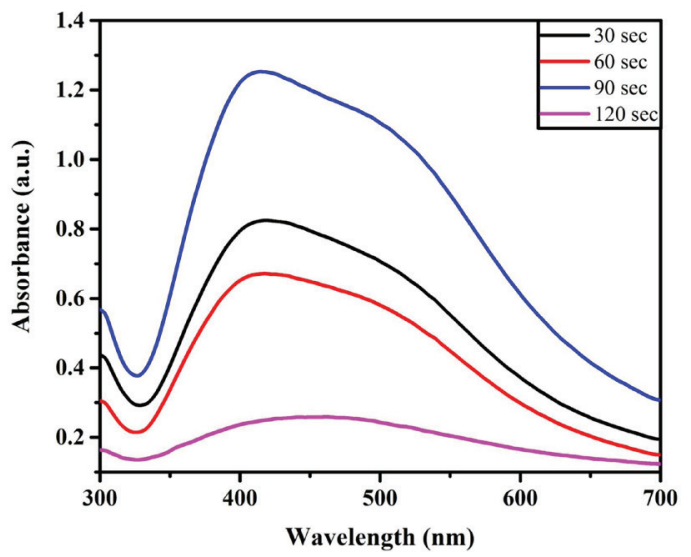

Fig. 3. UV-vis spectra of microwave assisted AgNPs synthesis. (For colour resolution see the on-line edition)

\section{Physicochemical characterization of silver nanoparticles}

DLS was performed with freshly prepared ANB-AgNPs in suspension. The study revealed the average hydrodynamic size of AgNPs in the range of $56 \mathrm{~nm}$ (Fig. 4A). Furthermore, the PDI (Poly dispersive index) was found to be 0.2 attributed to the homogenous synthesis of particles. The charge on the particles was assessed by zeta analysis and the resulted zeta potential was $-16.6 \mathrm{mV}$ (Fig. 4B).
Further, FESEM was conducted to investigate the size and morphology of synthesized ANB-AgNPs. Accordingly (Fig. 5A), it was evident that the ANB-AgNPs were spherical in shape having a smooth surface. The image also revealed that the average particles were found to be around 20-50 nm without any aggregation. The representative EDS spectrum (Fig. 5B) showed the absorption spectrum with an intense high peak at $3 \mathrm{keV}$. It is a characteristic absorption for metallic silver confirming the purity of our synthesized AgNPs (Vijayaraghavan et al., 2012). The presence of a very small peak of aluminum along with silver might be due to the aluminium stub that was used for sample loading and analysis.

FTIR spectrum was conducted to evaluate the functional groups present in the extract with their possible interactions that involved in AgNPs synthesis and stabilizing by capping. IR spectra of A. nilotica bark extract (Fig. 6 band A) showed peaks at $3352 \mathrm{~cm}^{-1}$ and $3058 \mathrm{~cm}^{-1}$ indicating the presence of alcoholic and phenolic compounds. Further, peak at $1610 \mathrm{~cm}^{-1}$ indicates N-H stretching between the bonds. Further, IR-spectra of AgNPs (Fig. 6 band B) showed a peak at $3493 \mathrm{~cm}^{-1}$ that also revealed the involvement of alcoholic and phenolic compounds as in extract indicating that these are responsible for AgNPs synthesis by reduction. The peak around 2431 and 2398 indicates the presence of aldehyde group in both extract and AgNPs with slight difference showing the involvement of these functional group. The peaks at $1769 \mathrm{~cm}^{-1}, 1610 \mathrm{~cm}^{-1}$ and $1580 \mathrm{~cm}^{-1}$ shows that aromatic compounds and proteins are involved in interaction and providing capping for the stability of ANB-AgNPs (Zayed et al., 2012). 

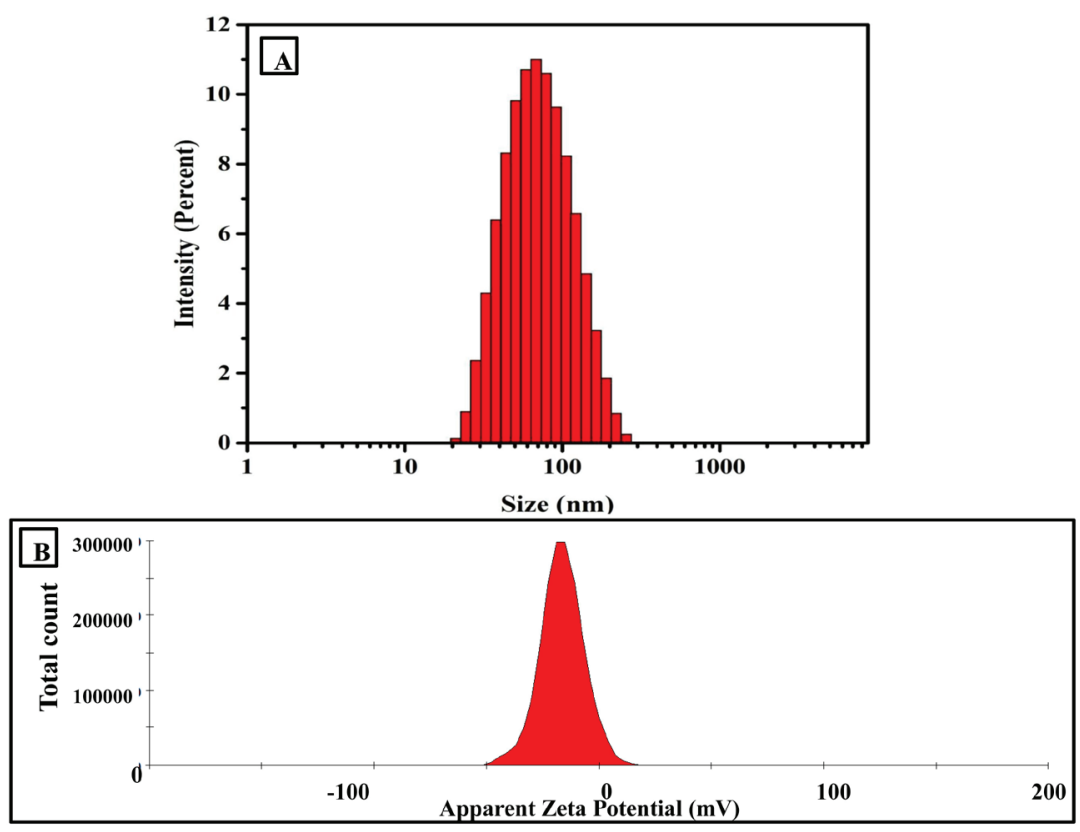

Fig. 4. (A) Dynamic light scattering data that depict hydrodynamic diameter in the range of $56 \mathrm{~nm}$ with a PDI range of 0.2; (B) Zeta analysis showing zeta potential -16.6.
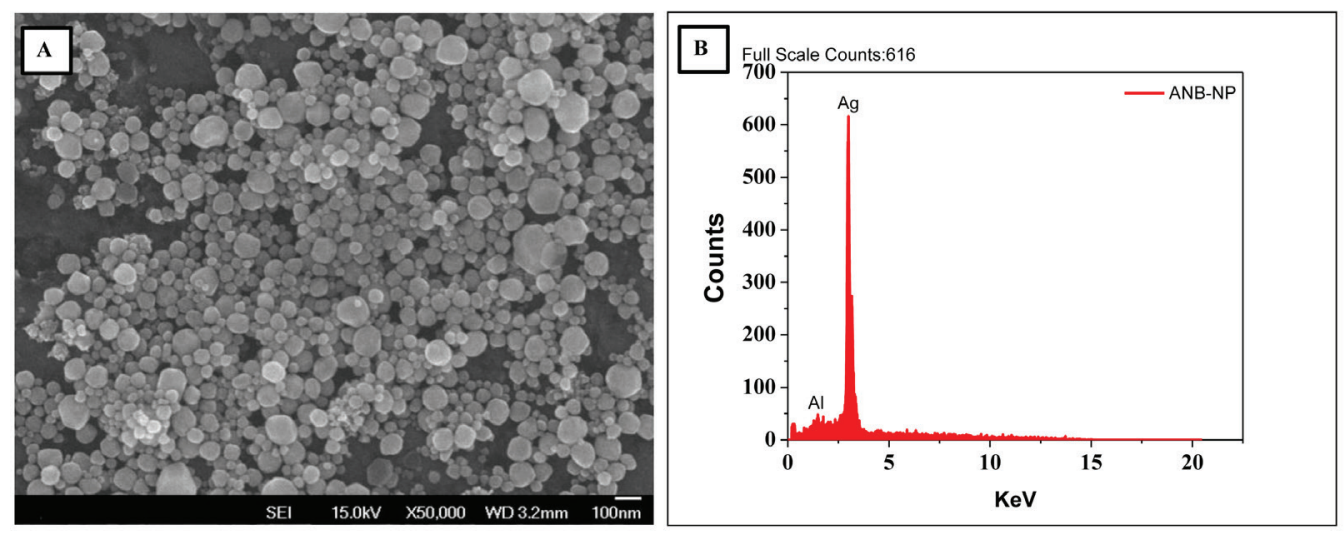

Fig. 5. (A) FESEM data depicting size 10-20 nm and spherical morphology without any aggregation; (B) EDS spectrum of AgNPs showing a strong characteristic peak of silver without any impurity.

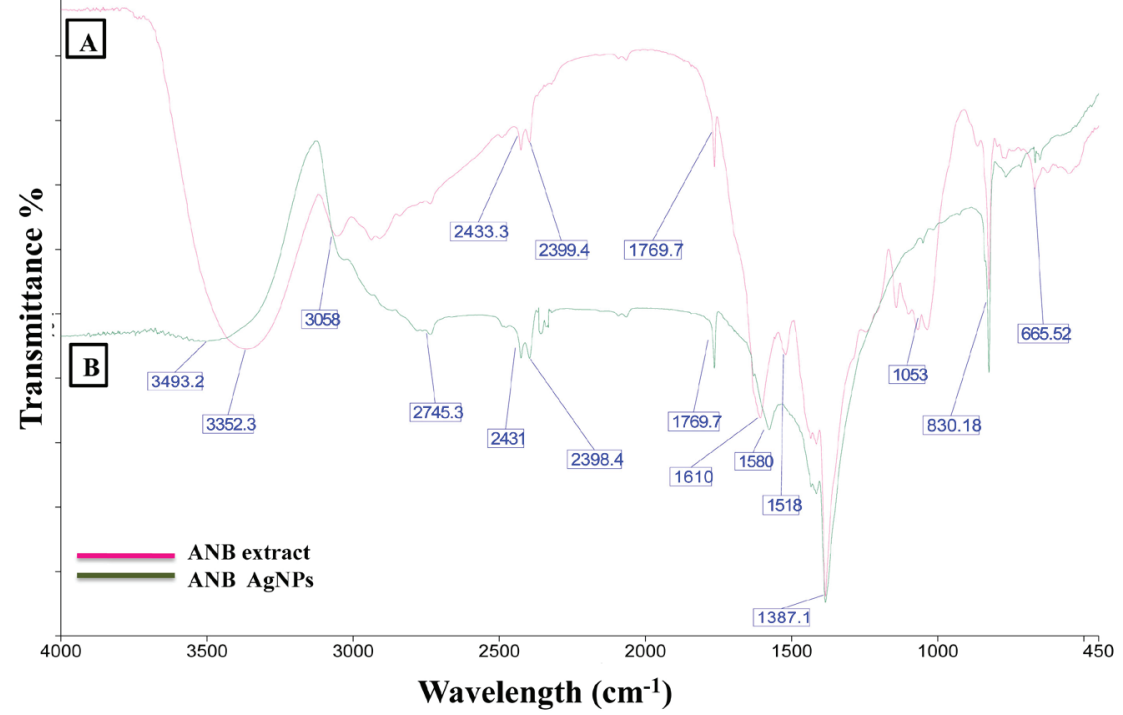

Fig. 6. FTIR spectra of AgNPs (A) band of leaf extract only; (B) band of synthesized AgNPs. (For colour resolution see the on-line edition) 


\section{Evaluation of antibacterial activity using disc diffusion assay}

The potent antibacterial efficacy of ANB-AgNPs was investigated using disc diffusion assay against $E$. coli and multi-drug resistant $P$. aeruginosa on LB agar plates (Saravanan et al., 2018). In both the cases, the antibacterial activity was evaluated by employing assay for stipulated concentrations $(0.25,0.5$, 0.75 and $1 \mu \mathrm{g}$ ) of AgNPs on discs (C, D, E, F). Disc 'A' and 'B' was taken as negative and the positive control with autoclaved deionized water and antibiotic (kanamycin), respectively.
As evident from the image (Fig. 7A, B), the growth of bacteria was repressed in an appreciable manner. Furthermore, the zone of inhibition for both the bacteria was quantitatively presented by bar graph (Fig. 7C) dictating the concomitant decrease in the growth rate with increase in the concentration of ANB-AgNPs from $0.25 \mu \mathrm{g}$ to $1 \mu \mathrm{g}$. The results indicate that the antibacterial potential was highly dose-dependent, and it can also surmount the problem of multi-drug resistance. The diameter of the zone of inhibition was presented in $\mathrm{mm}$ and taken as mean \pm SD of duplicates.
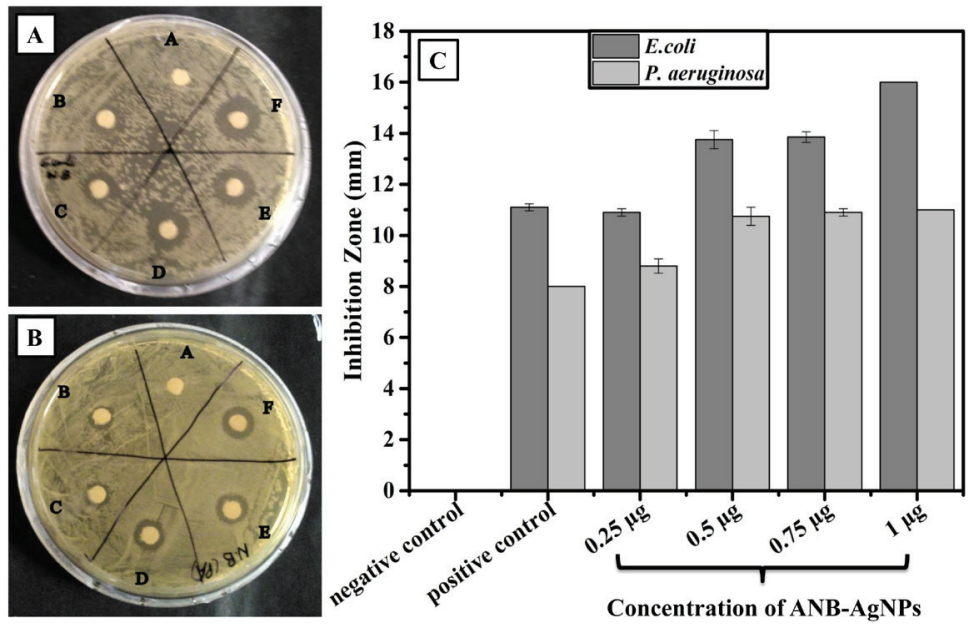

Fig. 7. Representative results of antibacterial assay of AgNPs by using disc diffusion assay against (A) E. coli; (B) P. aeruginosa; (In both cases: A is negative control, B is positive control, and C to F mark different concentration of AgNPs); (C) Quantitative evaluation of zone of inhibition of both E. coli and P. aeruginosa that indicate antibacterial efficacy in a dose dependent manner.

\section{Anti-biofilm activity of ANB-AgNPs by CRA plate method}

Congo red agar plate method was performed to evaluate the anti-biofilm potential of ANB-AgNPs against two Gram-positive bacteria B. subtilis, $S$. aureus and two Gram-negative bacteria $P$. vulgaris, $P$. aeruginosa. Fig. 8 shows the results of the experiment which indicates the appearance of dry crystalline black colonies on the plate [A (i), B (i), C (i) and D (i)] where AgNPs were not supplemented. These black colonies were due to the exopolysaccharide production by the bacteria which is the prerequisite for the biofilm formation.
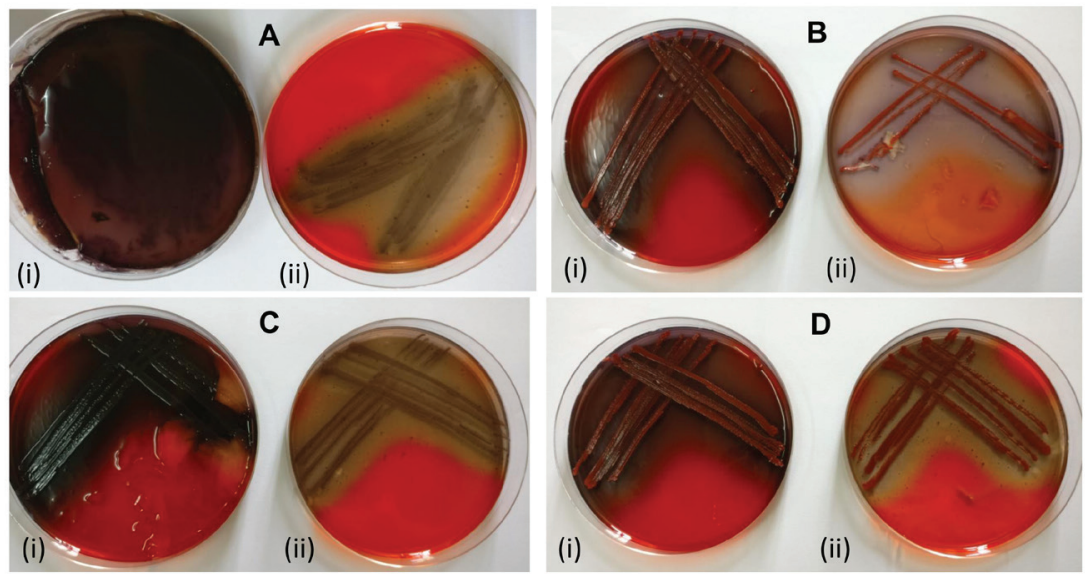

Fig. 8. Evaluation of the antibiofilm activity of ANB-AgNPs by CRA plate method. The appearance of black colonies [A (i), B (i), C (i) and D (i)] indicates the exopolysaccharide production by (A) Bacillus subtilis; (B) Staphylococcus aureus; (C) Proteus vulgaris; (D) Pseudomonas aeruginosa bacteria, respectively. Whereas the addition of ANB-AgNPs blocked the exopolysaccharide secretion by bacteria and weakened their growth.

(For colour resolution see the on-line edition) 
On the other hand, the plates which were supplemented with ANB-AgNPs [A (ii), B (ii), C (ii) and D (ii)] the organism showed growth with considerable decrease in the dry crystalline black colonies indicating inhibition of exopolysaccharide secreation by AgNPs treatment.. These results indicate the anti-biofilm activity of ANB-AgNPs.

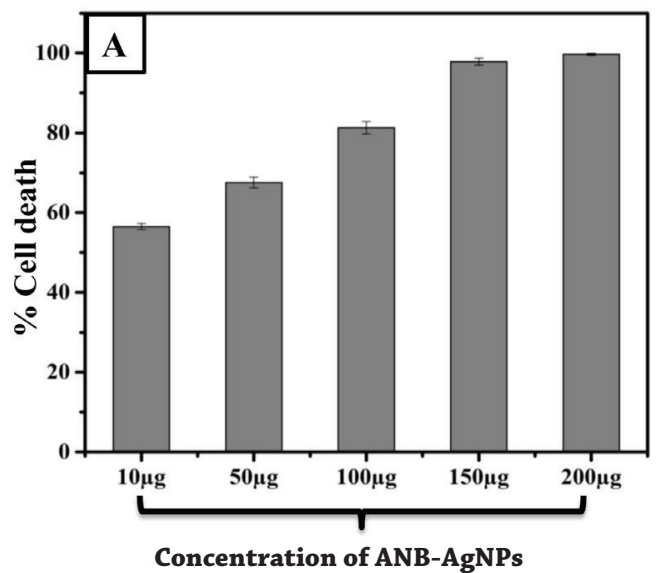

Evaluation of anticancer activity against $\mathbf{A 5 4 9}$ cell line The in vitro anticancer studies evidenced that ANB-AgNPs tends to possess potent anticancer activity. Fig. 9A shows a significant anti-cancerous activity of ANB-AgNPs from $10 \mu \mathrm{g}$ to $200 \mu \mathrm{g}$ in an increasing dose dependent manner where more than $80 \%$ of cell death was observed at $100 \mu \mathrm{g}$ that goes up to $98 \%$ at $200 \mu \mathrm{g}$.

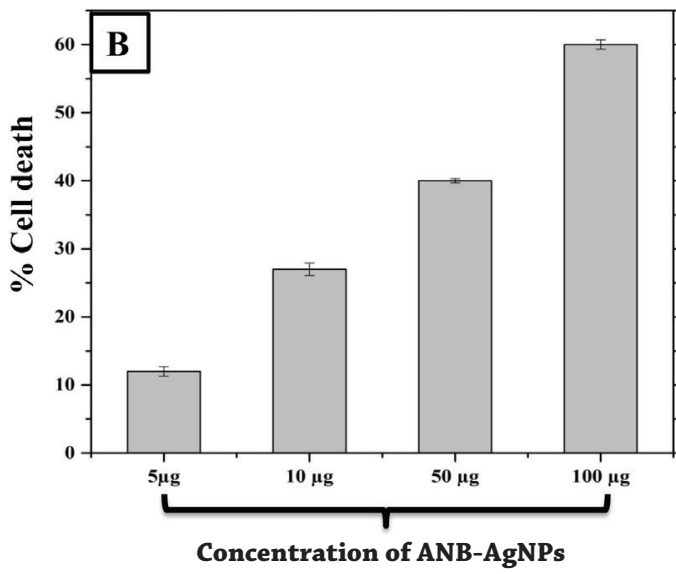

Fig. 9. Anticancer activity of synthesized AgNPs (A) against A549 cells; (B) against HEK 293 cells.

In case of cell viability assay that was performed against HEK 293 cells, the viability percentage decreased with increase of ANB-AgNPs concentration. However, when we compare the cell death percentage of both cancerous (A549) and non-cancerous cells (HEK 293) it was observed that at same concentration i.e. at $100 \mu \mathrm{g}$ the cell death was more than $80 \%$ in A549 cells that indicates only 20\% viable cells, whereas in HEK 293 cells the viability was observed near $50 \%$. These results clearly suggest the anticancer activity of ANB-AgNPs.

\section{Animal experiment for wound healing}

The wound healing percentage was quantified from the images taken after treatment by calculating the size reduction after 1 ,
6, 10 and 15 days. Fig. 10A shows the visual observation in the size reduction of the wounds. The rate of wound closure in the mice treated with ANB-AgNPs-Carbopol was much faster than the other two groups (Carbopol only and Povidine-Iodine). The group-I treated with Carbopol only, the percentage of wound healing was 25, 50 and 65 after 6, 10 and 15 days, respectively (Fig. 10B). Whereas in group-II (treatment of ANB-AgNPs-Carbopol), the percentage of wound healing was 60,80 and 99. Further, for group-III where the wound was treated with Povidine-iodine the percentage of wound healing was 12, 56 and 90. These results confirmed that ANB-AgNPs-Carbopol promoted wound contraction and accelerated the healing of wounds.
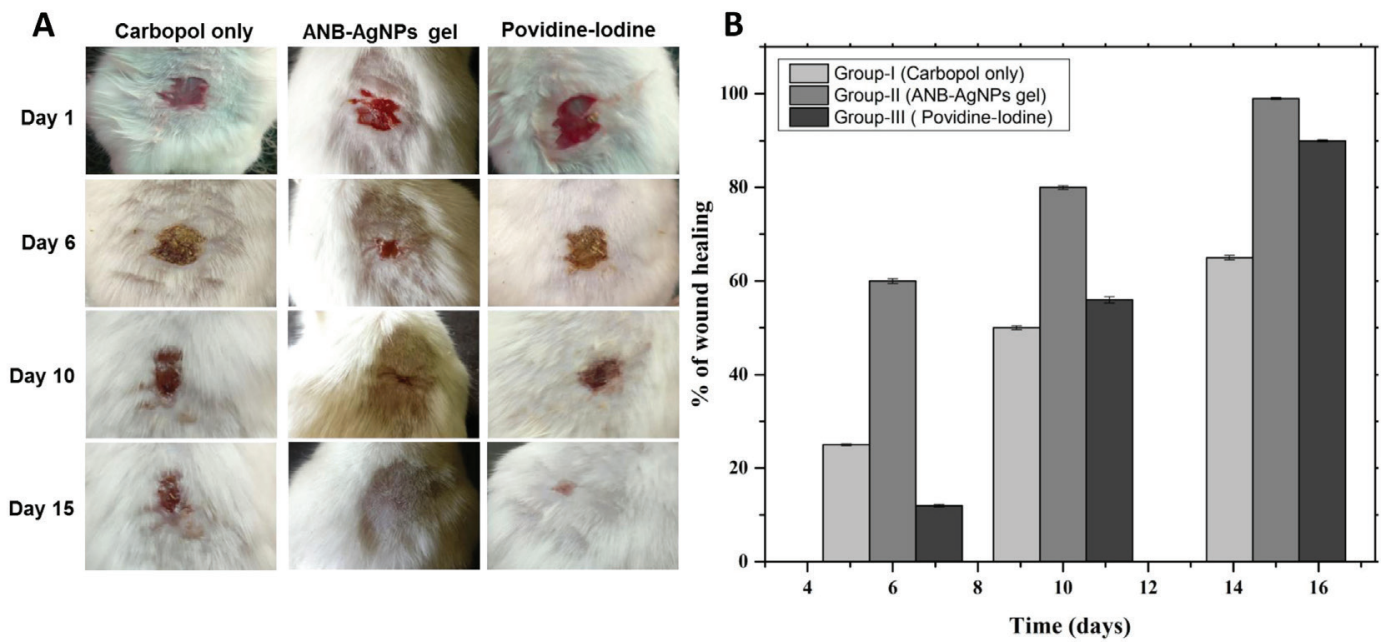

Fig. 10. (A) Photographs of the wound healing activity of all the three groups on 0, 6, 10 and 15 days under the treatment of Carbopol only, ANBAgNPs, Povidine-Iodine. (B) Quantitative data showing the \% of wound healing after treatment. 


\section{Conclusions}

The work represented here showed efficient synthesis of smallsized AgNPs using bark extract of A. nilotica. Optimization reactions suggested that the efficient biosynthesis of AgNPs occured when the reaction was performed using $0.1 \mathrm{mM} \mathrm{AgNO}_{3}$ at $25{ }^{\circ} \mathrm{C}$ for $20 \mathrm{~min}$ at an extract to $\mathrm{AgNO}_{3}$ ratio of $1: 10$. The results qualitatively depicted the particles were spherical in shape with the smaller size. Additionally, quantitative evaluation by DLS, FESEM showed size in the range of $10-50 \mathrm{~nm}$ and spherical morphology along with smooth surface. The synthesized ANB-AgNPs also have potent antibacterial and significant anti-biofilm activity against Gram-positive and Gram-negative bacteria. The anticancer activity of ANB-AgNPs come in a considerable manner even at a very low concentration. Further, wound healing assay showed that the synthesized ANB-AgNPs exhibit the contraction of wound and promote wound healing very efficiently within 15 days.

\section{Conflict of interests}

The authors declare that they have no competing interests.

\section{Acknowledgements}

Geeta Arya acknowledges for Senior Research Fellowship (SRF) from CSIR, Government of India and R. Mankamna Kumari acknowledges for SRF from ICMR, Government of India. Surendra Nimesh acknowledges the financial assistance from Department of Biotechnology (DBT) (grant no. 6242-P82/ RGCB/PMD/DBT/SNMH/2015), Government of India.

\section{References}

Ahmed Q, Gupta N, Kumar A, Nimesh S (2016). Antibacterial efficacy of silver nanoparticles synthesized employing Terminalia arjuna bark extract. Artif Cells Nanomed Biotechnol 45(6): 1-9. DOI: 10.1080/21691401.2016.1215328.

Ajitha B, Reddy YAK, Reddy PS, Suneetha Y, Jeon H-J, Ahn CW (2016). Instant biosynthesis of silver nanoparticles using Lawsonia inermis leaf extract: Innate catalytic, antimicrobial and antioxidant activities. J Mol Liq 219: 474-481. DOI: 10.1016/j. molliq.2016.03.041.

Ali A, Akhtar N, Khan BA, Khan HM, Rasul A, Khalid N, Waseem K, et al. (2012). Acacia nilotica: A plant of multipurpose medicinal uses. J Med Plant Res 6: 1492-1496. DOI: 10.5897/ JMPR11.1275.

Ansari MA, Khan HM, Khan AA, Cameotra SS, Alzohairy MA (2015). Anti-biofilm efficacy of silver nanoparticles against MRSA and MRSE isolated from wounds in a tertiary care hospital. Indian J Med Microbiol 33(1): 101-109. DOI: 10.4103/0255-0857.148402.

Arya G, Kumar N, Gupta N, Kumar A, Nimesh S (2016). Antibacterial potential of silver nanoparticles biosynthesized using Canarium ovatum leaves extract. IET Nanobiotechnol 11(5): 506-511. DOI: 10.1049/iet-nbt.2016.0144.

Arya G, Sharma N, Ahmed J, Gupta N, Kumar A, Chandra R, Nimesh S (2017). Degradation of anthropogenic pollutant and organic dyes by biosynthesized silver nano-catalyst from Cicer arietinum leaves. J Photochem Photobiol B 174: 90-96. DOI: 10.1016/j.jphotobiol.2017.07.019.

Balakumar V, Prakash P, Muthupandi K, Rajan A (2017). Nanosilver for selective and sensitive sensing of saturnism. Sens Actuators B Chem 241: 814-820. DOI: 10.1016/j.snb.2016.10.142.

Boisselier E, Astruc D (2009). Gold nanoparticles in nanomedicine: preparations, imaging, diagnostics, therapies and toxicity. Chem Soc Rev 38(6): 1759-1782. DOI: 10.1039/b806051g.

Emmanuel R, Saravanan M, Ovais M, Padmavathy S, Shinwari ZK, Prakash P (2017). Antimicrobial efficacy of drug blended biosynthesized colloidal gold nanoparticles from Justicia glauca against oral pathogens: a nanoantibiotic approach. Microb Pathog 113: 295-302. DOI: 10.1016/j.micpath.2017.10.055.

Gong CP, Li SC, Wang RY (2018). Development of biosynthesized silver nanoparticles based formulation for treating wounds during nursing care in hospitals. J Photochem Photobiol B 183: 137-141. DOI: 10.1016/j.jphotobiol.2018.04.030.

Jeeva K, Thiyagarajan M, Elangovan V, Geetha N, Venkatachalam P (2014). Caesalpinia coriaria leaf extracts mediated biosynthesis of metallic silver nanoparticles and their antibacterial activity against clinically isolated pathogens. Ind Crop Prod 52: 714-720. DOI: 10.1016/j.indcrop.2013.11.037.

Kalishwaralal K, BarathManiKanth S, Pandian SRK, Deepak V, Gurunathan S (2010). Silver nanoparticles impede the biofilm formation by Pseudomonas aeruginosa and Staphylococcus epidermidis. Colloids Surf B: Biointerfaces 79(2): 340-344. DOI: 10.1016/j.colsurfb.2010.04.014.

Karuppiah C, Palanisamy S, Chen S-M, Emmanuel R, Ali MA, Muthukrishnan P, Prakash, P, Al-Hemaid FM (2014). Green biosynthesis of silver nanoparticles and nanomolar detection of p-nitrophenol. J Solid State Electr 18(7): 1847-1854.

Kaviya S, Santhanalakshmi J, Viswanathan B, Muthumary J, Srinivasan K (2011). Biosynthesis of silver nanoparticles using citrus sinensis peel extract and its antibacterial activity. Spectrochim Acta A Mol Biomol Spectrosc 79(3): 594-598. DOI: 10.1016/j.saa.2011.03.040.

Kumari RM, Thapa N, Gupta N, Kumar A, Nimesh S (2016). Antibacterial and photocatalytic degradation efficacy of silver nanoparticles biosynthesized using Cordia dichotoma leaf extract. Adv Nat Sci Nanosci Nanotech 7(4): 045009.

Lukman AI, Gong B, Marjo CE, Roessner U, Harris AT (2011). Facile synthesis, stabilization, and anti-bacterial performance of discrete Ag nanoparticles using Medicago sativa seed exudates. J Colloid Interface Sci 353(2): 433-444. DOI: 10.1016/j.jcis.2010.09.088.

Mie G (1976). Contributions to the optics of turbid media, particularly of colloidal metal solutions. Contributions to the optics of turbid media, particularly of colloidal metal solutions Transl. into ENGLISH from Ann. Phys.(Leipzig) 25(3): 377-445.

Moideen M, Varghese R, Kumar E, Dhanapal C (2011). Wound healing activity of ethanolic extract of Hemidesmus indicus (Linn) $\mathrm{R}$. Br leaves in rats. Res J Pharm Biol Chem Sci 2(3): 643-651.

Nakkala JR, Mata R, Gupta AK, Sadras SR (2014). Biological activities of green silver nanoparticles synthesized with Acorous calamus rhizome extract. Eur J Med Chem 85: 784-794. DOI: 10.1016/j.ejmech.2014.08.024.

Narayanan KB, Sakthivel N (2011). Extracellular synthesis of silver nanoparticles using the leaf extract of Coleus amboinicus Lour. Mat Res Bull 46(10): 1708-1713. DOI: 10.1016/j. materresbull.2011.05.041.

Ong C, Lim JZ, Ng CT, Li JJ, Yung LY, Bay BH (2013). Silver Nanoparticles in Cancer Therapeutic Efficacy and Toxicity. Curr Med Chem 20(6): 772-781. DOI: 10.2174/0929867311320060003.

Pradeepa M, Harini K, Ruckmani K, Geetha N (2014). Extracellular bio-inspired synthesis of silver nanoparticles using raspberry leaf extract against human pathogen. Int J Pharm Sci Rev Res 25(2): $160-165$

Prasad M (2015). Synthesis of silver nanoparticles from the methanolic extract of Acacia nilotica bark and evaluating its antibacterial activity using multi-drug resistant bacteria. IJSET 3 : 1029-1033.

Preethy B, Savitha C (2016). A Comparative Study on Antibacterial Activity of Herbs with its Nanoparticle. IRJET 03(1): 840-844.

Saravanan M, Barik SK, Mubarakali D, Prakash P, Pugazhendhi A (2018). Synthesis of silver nanoparticles from Bacillus brevis (NCIM 2533) and their antibacterial activity against pathogenic bacteria. Microb Pathog 116: 221-226. DOI: 10.1016/j. micpath.2018.01.038.

Sathishkumar M, Sneha K, Won SW, Cho CW, Kim S, Yun YS (2009). Cinnamon zeylanicum bark extract and powder mediated green synthesis of nano-crystalline silver particles and its bactericidal activity. Colloids Surf B Biointerfaces 73(2): 332-338. DOI: 10.1016/j.colsurfb.2009.06.005. 
Singh P, Kim YJ, Wang C, Mathiyalagan R, Yang DC (2016a). The development of a green approach for the biosynthesis of silver and gold nanoparticles by using Panax ginseng root extract, and their biological applications. Artif Cells Nanomed Biotechnol 44(4): 1150-1157. DOI: 10.3109/21691401.2015.1011809.

Singh P, Kim YJ, Wang C, Mathiyalagan R, Yang DC (2016b). Weissella oryzae DC6-facilitated green synthesis of silver nanoparticles and their antimicrobial potential. Artif Cells Nanomed Biotechnol 44(6): 1569-1575. DOI: 10.3109/21691401.2015.1064937.

Stamplecoskie KG, Scaiano JC (2010). Light emitting diode irradiation can control the morphology and optical properties of silver nanoparticles. J Am Chem Soc 132(6): 1825-1827. DOI: $10.1021 /$ ja910010b.

Vasanth K, Ilango K, Mohankumar R, Agrawal A, Dubey GP (2014). Anticancer activity of Moringa oleifera mediated silver nanoparticles on human cervical carcinoma cells by apoptosis induction. Colloids Surf B Biointerfaces 117: 354-359. DOI: 10.1016/j.colsurfb.2014.02.052.

Vellaichamy B, Periakaruppan P (2016a). A facile, one-pot and ecofriendly synthesis of gold/silver nanobimetallics smartened rGO for enhanced catalytic reduction of hexavalent chromium. RSC Advances 6(62): 57380-57388. DOI: 10.1039/C6RA10544K.
Vellaichamy B, Periakaruppan P (2016b). Green synthesized nanospherical silver for selective and sensitive sensing of $\mathrm{Cd}^{2+}$ colorimetrically. RSC Advances 6(42): 35778-35784. DOI: 10.1039/C6RA04381J.

Vellaichamy B, Periakaruppan P (2016c). Silver nanoparticleembedded RGO-nanosponge for superior catalytic activity towards 4-nitrophenol reduction. RSC Advances 6(91): 88837-88845. DOI: 10.1039/C6RA19834A.

Vijayaraghavan K, Nalini SP, Prakash NU, Madhankumar D (2012). Biomimetic synthesis of silver nanoparticles by aqueous extract of Syzygium aromaticum. Materials Letters 75: 33-35. DOI: 10.1016/j.matlet.2012.01.083.

Wilkinson LJ, White RJ, Chipman JK (2011). Silver and nanoparticles of silver in wound dressings: a review of efficacy and safety. J Wound Care 20(11): 543-549. DOI: 10.12968/ jowc.2011.20.11.543.

Zayed MF, Eisa WH, Shabaka AA (2012). Malva parviflora extract assisted green synthesis of silver nanoparticles. Spectrochim Acta A Mol Biomol Spectrosc 98: 423-428. DOI: 10.1016/j. saa.2012.08.072.

Zhang W, Qiao X, Chen J (2007). Synthesis of silver nanoparticles Effects of concerned parameters in water/oil microemulsion. Mat Sci Eng B 142(1): 1-15. DOI: 10.1016/j.mseb.2007.06.014. 